\title{
Solid Waste Management Issues in Small Towns of Developing World: A Case Study of Taxila City
}

\author{
Naeem Ejaz and Nasir Sadiq Janjua
}

\begin{abstract}
Solid waste management issues are increasing in developing world due to increase in population every year. Open dumping and irregular collections of solid waste are creating serious environmental threats in small towns of developing world. In Pakistan, poor solid waste management practices, lack of funds and irresponsible behavior of dwellers are reflecting the worst scenario in the country. To emphasize the major solid waste management issues in the small towns of developing world, Taxila city is selected as a case study. Taxila city is facing the worst solid waste management issues due to rapid urbanization, industrialization, insufficient funds and poor management. Open dumps of municipal solid waste are causing serious negative environmental impacts in the study area. Research findings are clearly indicating that due to rapid growth in population, increments in solid waste generation rate, poor management, non-implementation of solid waste legislation and lack of funding are responsible for the solid waste management crises in the Taxila city. Faulty solid waste management system is creating negative environmental impacts like land and water pollution, infectious diseases, blockage of open drain and small canals and loss of biodiversity in Taxila city.
\end{abstract}

Index Terms-Solid waste management, taxila city, environmental issues, land pollution.

\section{Solid Waste Management Crises in Developing WORLD}

Solid waste management crises are directly related to the human health, economy and environment. In developing world, solid waste management authorities are seriously facing the associated problems in collection, transportation and disposal of communal solid waste. In Pakistan, due to improper planning and lack of funding the solid waste management crises are turning into worst [1]. Open dumps of municipal solid waste (MSW) are responsible for the number of vector diseases in Pakistan [2]. Increase in per capita solid waste generation rate is another serious threat for the management authorities in the developing world. Due to diverse living practices in same town, management authorities can not provide uniform solid waste management system, therefore in Pakistan so many non-technical solid waste management systems are working. Due to shortage of proper collection bins in Pakistan, the collection efficiency is very low. Open dumping, open burning and improper sanitary landfills can be observed everywhere in the country [1]. According to the Ministry of Environment Pakistan, in

Manuscript received January 31, 2012; revised March 11, 2012.

Naeem Ejaz is with the Department of Civil Engineering, University of Engineering \& Technology Taxila, Pakistan (Email: naeem.ejaz@uettaxila.edu.pk). urban areas more than 54,850 tons of solid waste is being generated every day but unfortunately less than 50 percent of generated solid waste is being collected [3] \& [4].

\section{INTRODUCTION TO THE STUDY AREA}

The Taxila city was selected as a case study during the investigation. The study area is about $25 \mathrm{Km}$ from the capital of Pakistan. The city is surrounded by so many reputed industrial zones like Pakistan Ordinance Factories, Heavy Industries of Taxila, Heavy Mechanical Complex, Air Weapon Complex, Hattar Industrial Estates etc. The climate of the Taxila city is humid subtropical with average rainfall of $990 \mathrm{~mm}$. Most of the rainfall in study area occurs during monsoon. The overall efficiency of municipal solid waste management system in the study area is not up to satisfactory. Tehsil Municipal Administration (TMA) Taxila is responsible for the collection, storage, transportation and disposal of generated solid waste. The location plan of Taxila city is shown in Fig. 1.

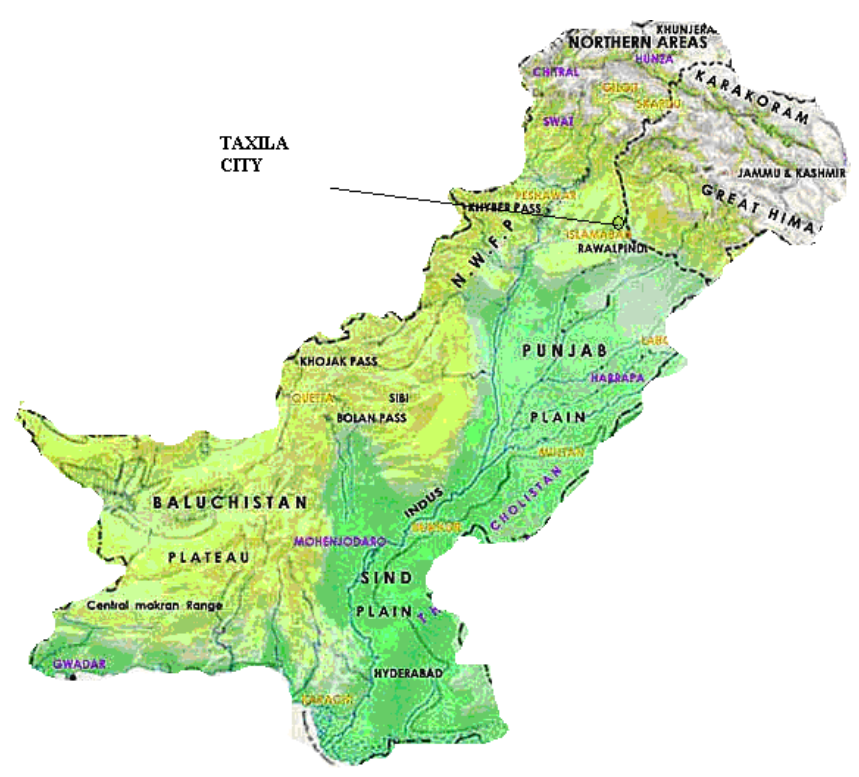

Fig. 1. Location map of Taxila city

\section{RESEARCH OBJECTIVES}

The major objective of this study was to investigate core issues related to the solid waste management in the small towns of developing world. Negative environmental impacts and other related issues due to defective management of municipal solid waste were also systematically examined during the field investigation. 


\section{Research Methodology}

Initial data related to the overall solid waste management system in Taxila city were collected form TMA to understand the existing practices. Other important information like collection and disposal systems, density and composition of solid waste, climate, living standard of dwellers etc were collected from the field visits and concerned departments. In-depth information related to the type of collection systems, waste composition, location of disposal sites, average generation rate per capita per day, types of containers, types of collection vehicles and number of designated staff were obtained from office of TMA and site visits.

On the behalf of restored data from concerned departments and the field visits, the study area was divided into three main parts, newly planned developed areas, old unplanned developed areas and commercial developed areas. Then solid waste management crises from these areas were deeply observed according to the requirement of research activity. Considering the indigenous environmental conditions and behavior of the local dwellers, technical suggestions are also discussed as the research findings.

\section{Solid Waste Management Issues in TaXila City}

Serious negative environmental impacts due to faulty handling of municipal solid waste can be observed in the Taxila city. Open dumping of municipal solid waste is a common practice in the study area. Main streets, roads, railway tracks, open drains and undeveloped plots in the study area have been seriously contaminated as shown in following figures from 2 to 6 . Many negative impacts due to faulty handling of solid waste can be seen in Taxia city as shown in the following figures. These impacts are explained in Table 1 in detail.

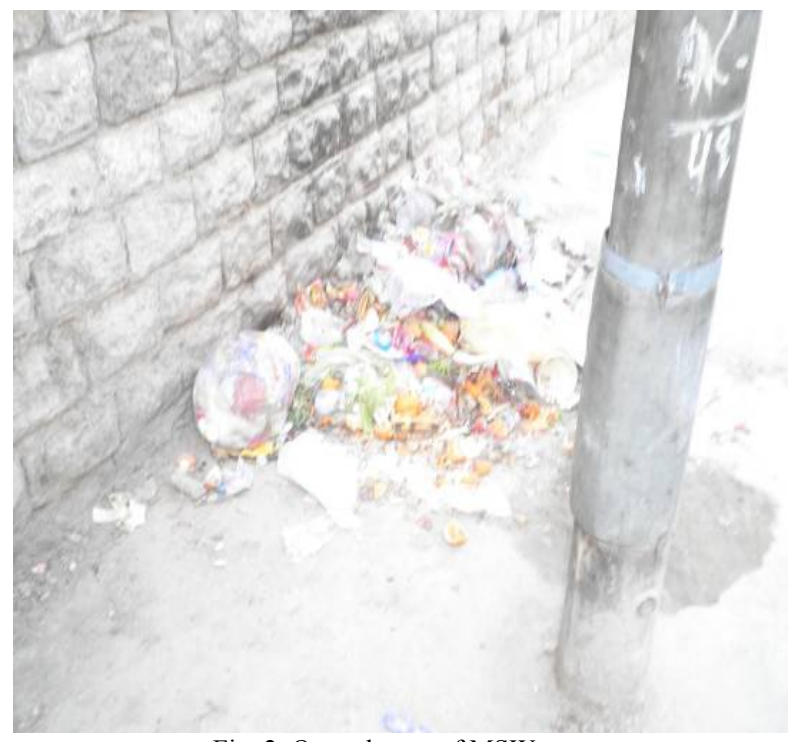

Fig. 2. Open dumps of MSW on streets

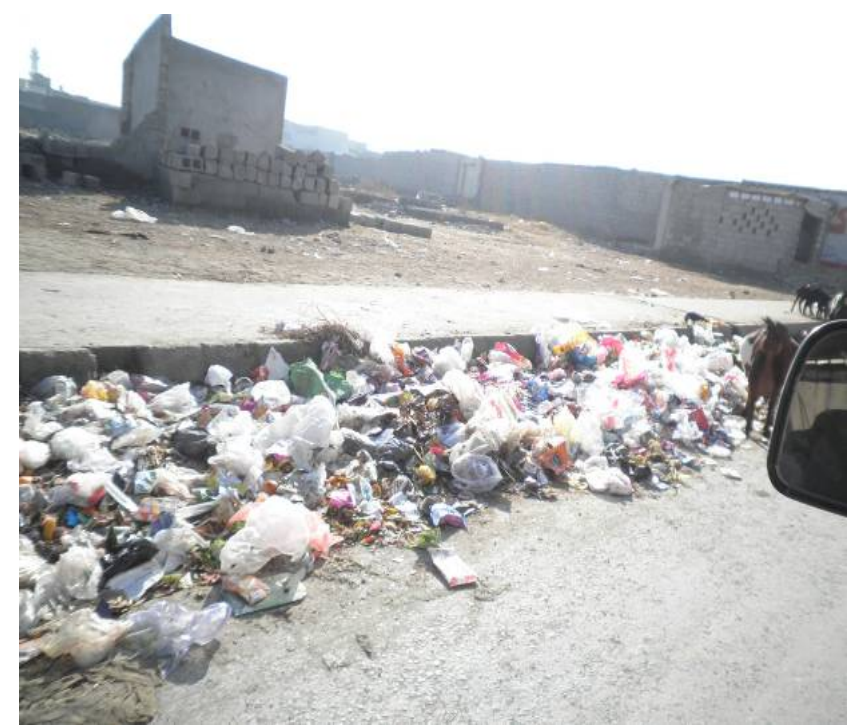

Fig. 3. Open dumps of MSW along road sides

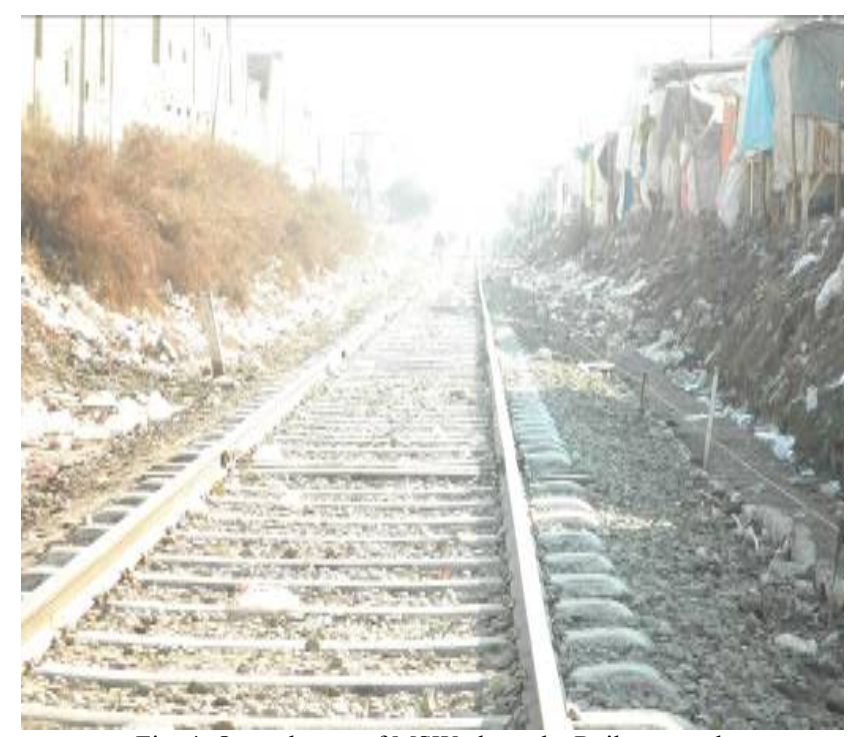

Fig. 4. Open dumps of MSW along the Railway track

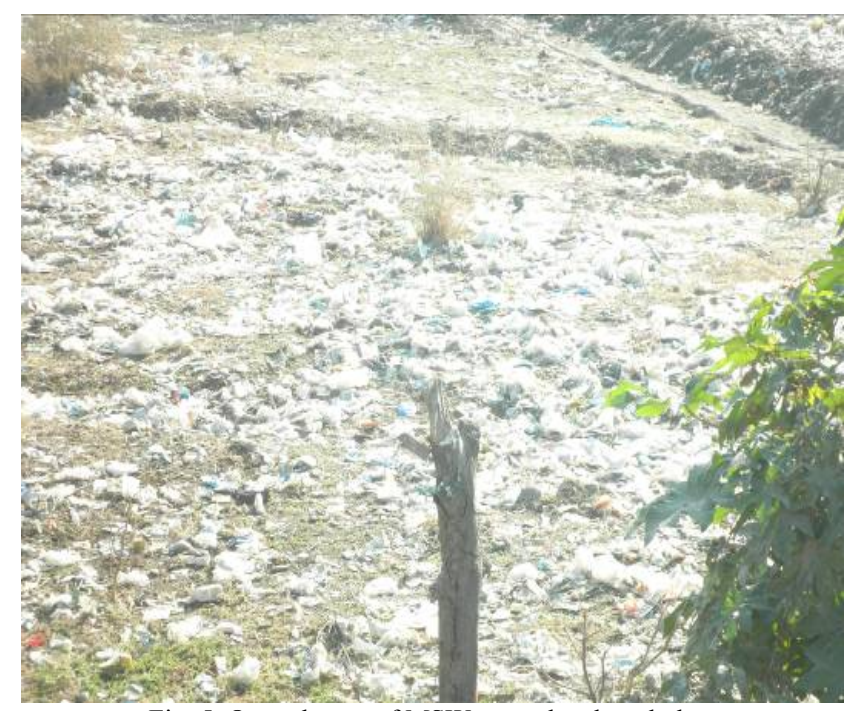

Fig. 5. Open dumps of MSW on undeveloped plots 


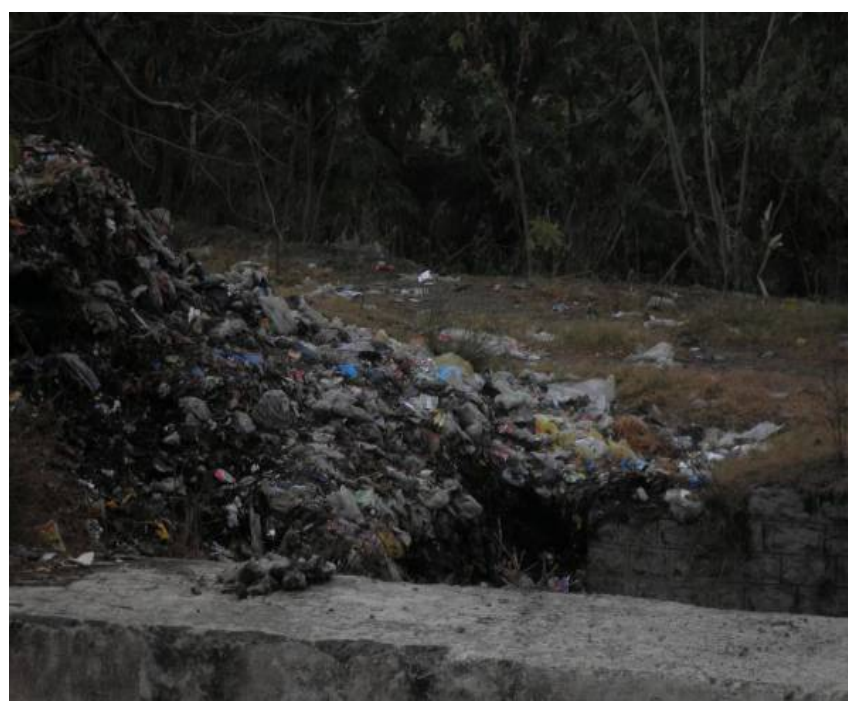

Fig. 6. Dumping of solid waste in drains

TABLE I: NEGATIVE IMPACTS DUE TO FAULTY HANDLING OF MSW

\begin{tabular}{|l|l|l|}
\hline $\begin{array}{l}\text { Sr. } \\
\text { No. }\end{array}$ & Problems/Issues & Associated negative impacts \\
\hline 1 & $\begin{array}{l}\text { Open dumping of MSW on } \\
\text { streets, roads, railway tract } \\
\text { etc }\end{array}$ & $\begin{array}{l}\text { Providing food and shelter for } \\
\text { disease causing animals. } \\
\text { Unhygienic conditions and smell } \\
{[3]-[10]}\end{array}$ \\
\hline 2 & $\begin{array}{l}\text { Dispersion of municipal } \\
\text { solid waste }\end{array}$ & $\begin{array}{l}\text { Blockage of open drain and } \\
\text { sewerage systems } \\
\text { Street flooding during rainy seasons } \\
\text { Unhygienic condition in living areas } \\
\text { Associated problems of leachate } \\
\text { [3]-[10] }\end{array}$ \\
\hline 3 & $\begin{array}{l}\text { Open burning of municipal } \\
\text { solid waste }\end{array}$ & $\begin{array}{l}\text { Producing air contaminants } \\
\text { Negative impacts on indoor and out } \\
\text { door air quality [3]-[10] }\end{array}$ \\
\hline 5 & $\begin{array}{l}\text { Lack of health and safety } \\
\text { measures for staff and } \\
\text { workers }\end{array}$ & $\begin{array}{l}\text { Occupational hazards to the worker, } \\
\text { including strains from lifting, } \\
\text { injuries from sharp objects and } \\
\text { traffic accidents. [3]-[10] }\end{array}$ \\
\hline \multirow{2}{*}{$\begin{array}{l}\text { transportation of MSW } \\
\text { and }\end{array}$} & $\begin{array}{l}\text { Totally unhygienic conditions } \\
\text { during transportation [3]-[10] }\end{array}$ \\
\hline
\end{tabular}

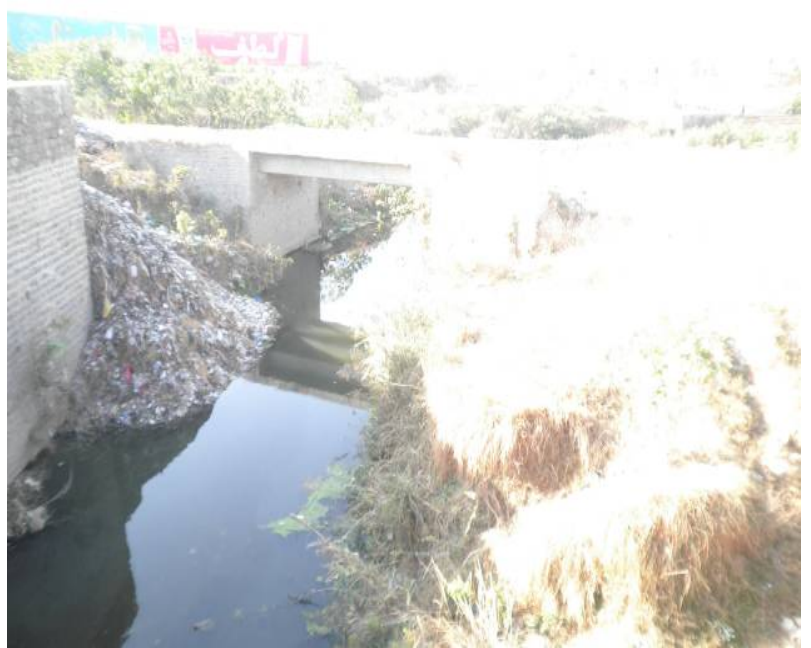

Fig. 7. Blockage of open drains due to solid waste dumps

\section{SOLID COLLECTION SYSTEM IN TAXILA CITY}

In Taxila city, solid waste is being collected manually by the help of sweepers [5]. They are normally using wheel borrows, hand carts and motorcycle rickshaws for the collection of solid waste from the streets. At most of the collection locations solid waste containers are not available and dwellers are dumping the solid waste on ground. The generated solid waste from these locations is being collected by the help of open body vehicles irregularly. The selected disposal site for the city is not suitable and producing negative environmental impacts on surrounding populations. Storage containers are not compatible with the existing system as shown in the figures $8 \& 9$. It is also observed during the investigation that number of containers and collection vehicles are not sufficient to handle the generated waste. Considering the field analysis, the medium size containers with maximum $4.5 \mathrm{ft}$ height may be more suitable under local conditions. The collection efficiency may be increased by the implementation of medium size containers, because at present large size containers are creating a lot of difficulties while handling of MSW in the town.

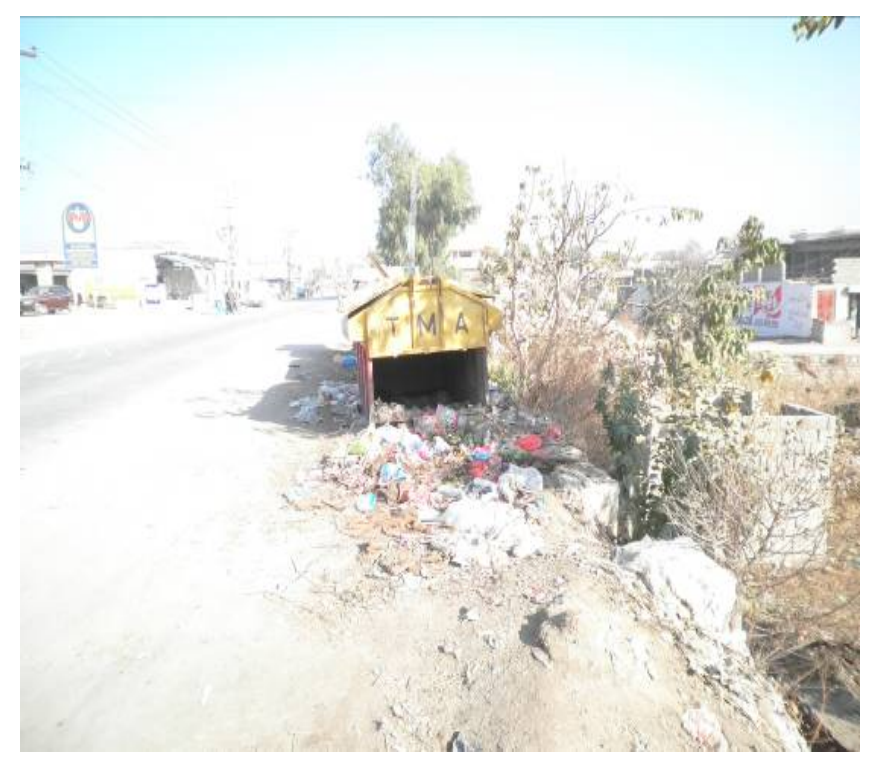

Fig. 8. Faulty Design of storage container in study area

\section{A. Disposal Practices}

Unfortunately, at present Tehsil Municipal Administration (TMA) Taxila has no appropriate landfill or waste disposal site. Open dumping and open burning of solid wastes is being practiced in the study area as shown in figures 10 and 11. Other types of dangerous wastes like chemical and hospital wastes are also not disposed of properly. 


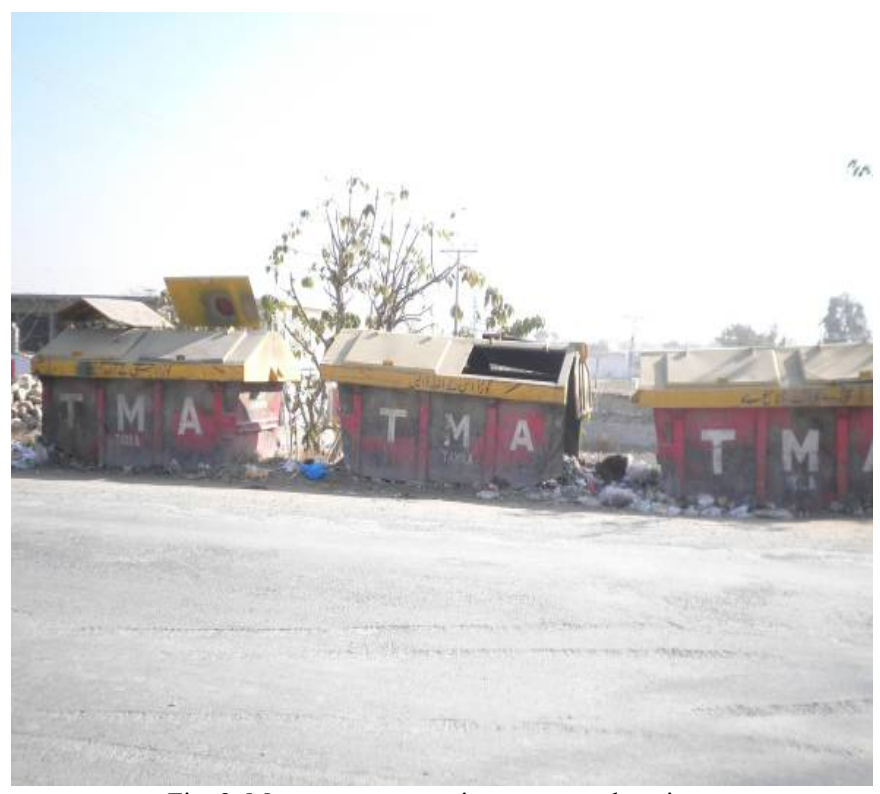

Fig. 9. More storage containers at same location

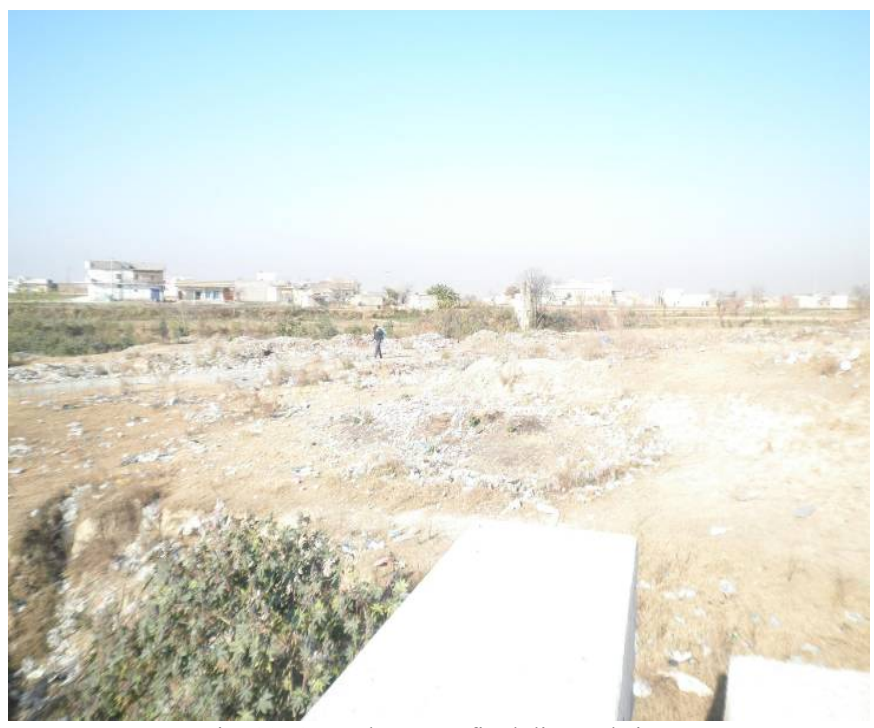

Fig. 10. Open dumps at final disposal site

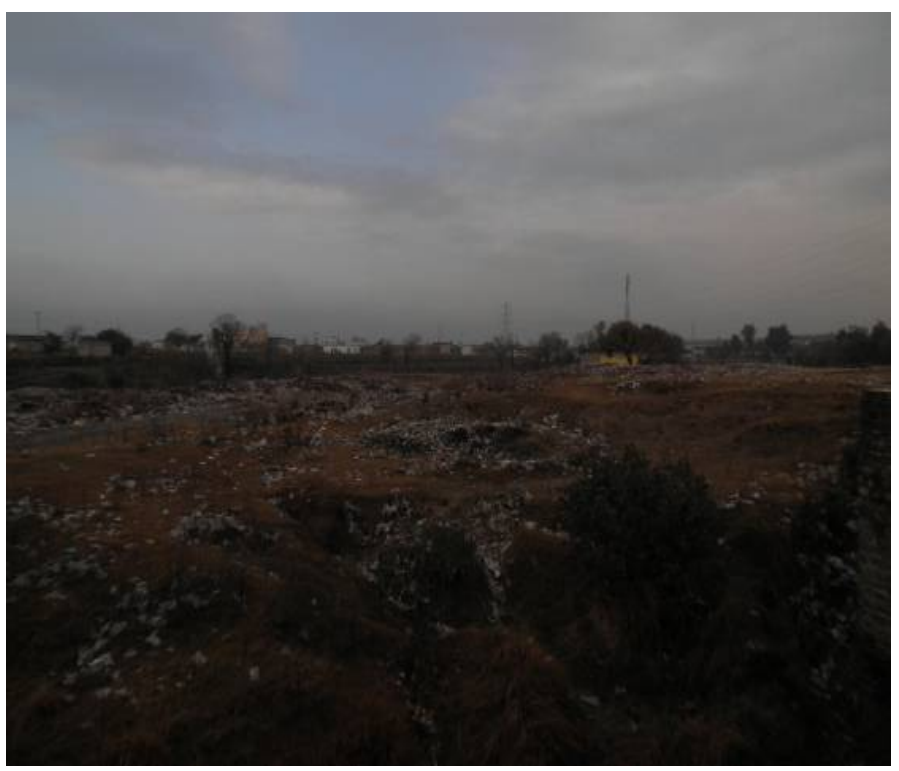

Fig. 11. Open dumps at disposal site under rain

\section{Serious EnVironmental Issues In Study Area Due TO OPEN DUMPING}

Open dumps of municipal solid waste are creating serious negative impacts on environment in Taxila city [8]. Many negative impacts are being observed in study area due to open dumping of solid waste. Heavy winds are spreading dust and filth from the open dumps to living areas and toxic gaseous emissions are continuously exposed to the atmosphere. It was also observed during the field visit that dumped solid waste at final disposal site is being burnt and creating drastic air pollution.

\section{CONCLUSION}

Developing countries are seriously struggling to design useful and economical solid waste management systems. In Taxila city, municipal solid waste is being dumped openly along roadsides. In study area a diverse solid waste management system is in practice. Open dumps are responsible for so many negative environmental impacts in the study area. Due to lack of funding and proper management the existing solid waste management system is not working successfully in Taxila city. Due to shortage of storage bins, collection efficiency is very low in study area. Special wastes like hospital waste and other hazardous materials are being disposed along with municipal solid waste. Considering the overall negative impacts associated with open dumping and open burning, these practices must be strongly discharged.

\section{Suggestions for Proper Disposal of Solid Waste}

Considering the present solid waste management situation in the Taxila city the following suggestions are being presented for the improvement of system.

1) Deficiency of staff, crews, vehicles and machinery must be recovered immediately.

2) Staff training programs must be initiated to motivate the workers.

3) Pen dumping and open burning of municipal solid waste are two major threats to the town environment, these kinds of practices must be discouraged through different awareness campaigns.

4) At present a reasonable amount of solid waste is being collected by the scavengers for recycling purposes, but they are not using any health and safety measures. These kinds of activities may be motivated while considering the proper health and safety measures.

5) Due to lack of available budget, the existing solid waste management system in not working effectively. The induction of small scale recycling plants by the municipal authority may generate a reasonable financial source in coming future.

6) Considering ethics and the town environment, the transportation of collected solid waste through open body vehicles must be discouraged.

7) At present, no proper sanitary landfill site is available for the final disposal of municipal solid waste. A proper sanitary landfill site while considering the all 
environmental aspects may be designated immediately to avoid the environmental hazards due to illegal open dumps of collected municipal solid waste.

8) Encouragement of crews through proper incentives may be adopted to improve the sanitation practices.

\section{ACKNOWLEDGMENT}

The University of Engineering \& Technology Taxila, Tehsil Municipal Administration (TMA) Taxila, Rawalpindi Development Authority (RDA) and their staff/workers are highly acknowledged for their support and data sharing.

\section{REFERENCES}

[1] Domestic Solid Waste Management in Pakistan, Japan International Corporation Agency (JICA), 2002.

[2] An Introduction to Rawalpindi Municipal Corporation, RMC, 1997.

[3] H. N. Hashmi, N. E. Malik, and N. S. Shah, "Solid Waste Management In Peshawar," International Conference, ESDev, COMSATS Abbottabad, 2007, vol. I, pp 999-1006.

[4] H. N. Hashmi, N. E. Malik, and J. Hussain, "Environmental Degradation Due To Improper Sanitary Landfills And Open Dumps Of Municipal Solid Waste," International Conference, ESDev, COMSATS Abbottabad, 2007, vol. I, pp.995-998.

[5] S. F. Khan, N. E. Malik, and M. Taseer, "Impacts Of Municipal Solid Waste Open Dumps On Environment," International Conference, ESDev, COMSATS Abbottabad, 2007, vol. I, pp.727-730.

[6] N. Saleem, N. E. Malik, and Z. Naushad, "Negative Impacts of Discarded Polythene Bags on Environment," International Conference, ESDev, COMSATS Abbottabad, 2007, vol. I, pp.973-980.
[7] H. N Hashmi., N. E. Malik, and Z. Naushad, "Environmental Benefits Of Composting Plants In Pakistan," International Conference, ESDev, COMSATS Abbottabad, 2007, vol. I, pp.919-92.

[8] H. N. Hashmi, N. E. Malik, and U. A. Naeem, "Environmental Impacts Of Improper Municipal Solid Waste Management," International Conference, ESDev, COMSATS Abbottabad, 2007, vol. I, pp.963-972.

[9] H. Nisar, N. Ejaz, Z. Naushad, Z. Ali "Impacts of solid waste management in Pakistan: a case study of Rawalpindi city," Waste Management and the Environment IV, WIT Press WIT Press, 2008, pp.379-388.

[10] N. Ejaz, N. Akhtar, H. N. Hashmi and U. A. Naeem, "Environmental impacts of improper solid waste management in developing countries: A case study of Rawalpindi city," The sustainable world, WIT Press, 2010, pp.379-388.

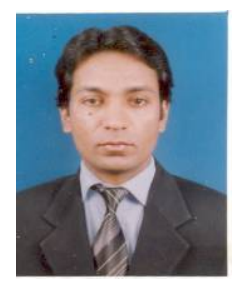

Dr. Naeem Ejaz is serving at the University of Engineering \& Technology Taxila-Pakistan and he is actively involve in teaching and research activities for last ten years. Dr. Ejaz did his bachelor degree (2001) in civil engineering and then master (2004) and doctorate (2009) in environmental engineering. He did research work for a year at University of Auckland, New Zealand on advance wastewater treatment technology.

He is currently engaged at Department of Civil Engineering at University of Engineering \& Technology Taxila-Pakistan in different research projects related to the environmental engineering. He also did some consultancy at one of the Pakistan's best consultant firm NESPAK for almost two years. During his stay he did many international projects related to the public health and environmental engineering.

Dr. Ejaz is enjoying life-time membership from Pakistan Engineering Council (PEC) as well. Dr. Ejaz has produced more than forty international research publications in the field of environmental engineering. He is also supervising different research projects at undergraduate and postgraduate levels related to the environmental engineering. 